\title{
Rare sugar D-allose induces programmed cell death in hormone refractory prostate cancer cells
}

\author{
Nibedita Naha $\cdot$ Hae Young Lee $\cdot$ Mi Ja Jo $\cdot$ Bong Chul Chung $\cdot$ \\ Sung Hoon Kim · Myeong Ok Kim
}

Published online: 6 May 2009

(C) Springer Science+Business Media, LLC 2009

\section{Erratum to: Apoptosis}

DOI 10.1007/s10495-008-0232-7

In the original version of this article, Fig. 3G on page 1129, the $x$-axis legend is not printed. For the reader's convenience, the correct Fig. 3 is reproduced here along with its legend.

\footnotetext{
Author Contributions: N. Naha: Study design, literature survey, experimental work, data interpretation, manuscript preparation; H. Y. Lee and M. J. Jo: Handling secondary culture; B. C. Chung: donated PrEC cell line; S. H. Kim: Fund collection (MRC);

M. O. Kim: Corresponding author, manuscript preparation, fund collection (KOSEF, MOEST, BK21).
}

The online version of the original article can be found under doi:10.1007/s10495-008-0232-7.

N. Naha $\cdot$ H. Y. Lee $\cdot$ M. J. Jo · M. O. Kim (ه)

Division of Life Science, Applied Life Science (Brain Korea 21

and EB-NCRC), Gyeongsang National University,

Jinju 660701, South Korea

e-mail: mokim@gsnu.ac.kr

N. Naha

e-mail: niv_639@yahoo.co.in

\section{B. C. Chung}

Bioanalysis and Biotransformation Research Centre, Korea Institute of Science and Technology, Cheongryang,

Seoul, South Korea

\section{S. H. Kim}

Cancer Preventive Material Development Research Centre (CPMDRC) and Institute College of Oriental Medicine, Kyunghee University, Seoul 130701, South Korea e-mail: sungkim7@khu.ac.kr; kim.sunghoon@mayo.edu 

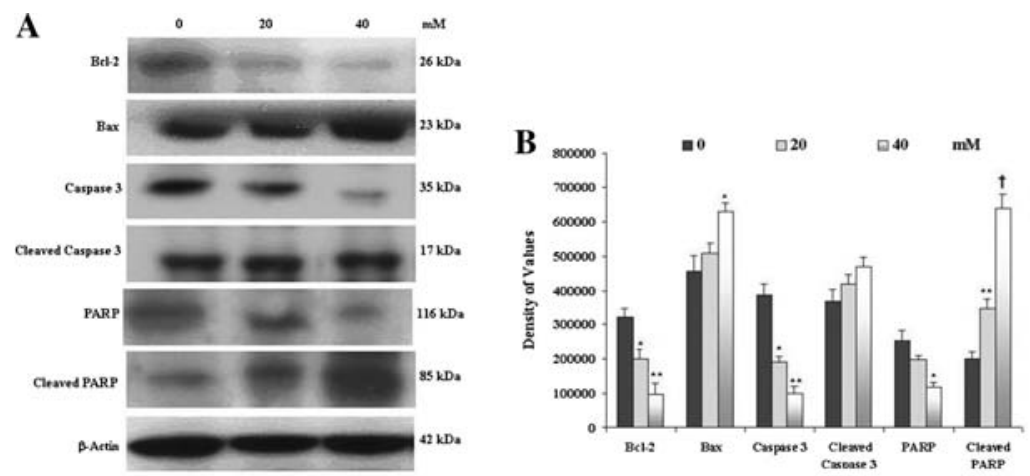

\section{Time (72 hr)}

C
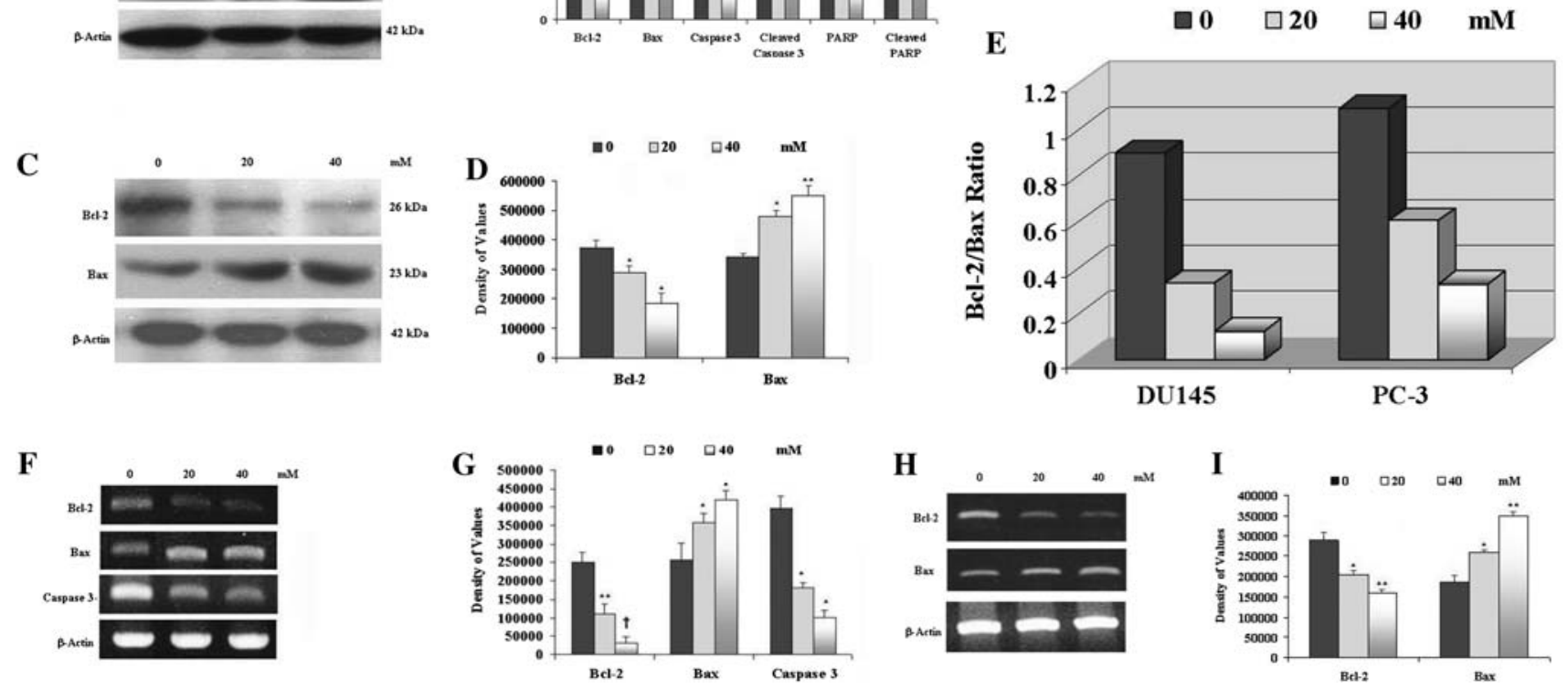

Fig. 3 Effects of D-allose on Bcl-2, Bax, caspase 3 and PARP expression levels in human HRPC cell lines, DU145 (A, B, E, F, G) and PC-3 (C, D, E, H, I). Cells are exposed to 0,20 and $40 \mathrm{mM}$ of D-allose for $72 \mathrm{~h}$. Detail procedures are mentioned in Material and Methods section. (A, C) After exposure cells are lysed and assayed for Bcl-2, Bax, full length caspase 3 and cleaved caspase 3, full length PARP and cleaved PARP proteins expression by Western blot analysis. $\beta$-actin expression indicates uniform loading in each lane. Results are the true representative of the triplicate experiments. (B, D) Densitometric evaluations of Bcl-2, Bax, full length caspase 3 and cleaved caspase 3 , full length PARP and cleaved PARP protein bands of (A) and (C), respectively by Sigma Gel, version 1.0. Results represent the mean \pm SEM of the three independent experiments. $* P<0.05,{ }^{*} * P<0.01,{ }^{\dagger} P<0.001$. (E) Bcl-2/Bax ratio of DU145 and $\mathrm{PC}-3$ cell lines on the basis of corresponding densitometry analysis of the protein bands after exposure. $(\mathbf{F}, \mathbf{H})$ Cells with and without D-allose treatments are subjected to analysis of Bcl-2, Bax and caspase 3 mRNAs by RT-PCR, where $\beta$-actin is taken as loading control. Results are the true representative of the triplicate experiments. (G, I) Densitometric analysis of Bcl-2, Bax and caspase 3 mRNA bands of $(\mathbf{F})$ and $(\mathbf{H})$, respectively by Molecular Analyst ${ }^{\mathrm{TM}}$, version 1.4.1. Results represent the mean \pm SEM of the three independent experiments. ${ }^{*} P<0.05,{ }^{*} P<0.01,{ }^{\dagger} P<0.001$ 